\title{
The future of Chemoecology
}

\section{Michael Heethoff ${ }^{1}$}

Published online: 22 May 2018

c) Springer International Publishing AG, part of Springer Nature 2018

It has been 5 years now that I have served as Editor in Chief for Chemoecology, together with a team of associate editors, to whom I here wish to express my deepest gratitude. During that time, we have moved the journal to an online-only publication with six issues per year. We have published some 140 articles that received more than 650 citations (May 2018). This was achieved by the whole editorial board and numerous reviewers, whom I here also wish to thank.

After 5 years, however, it is time for me to hand the baton to someone else. I am pleased that two of our associate editors, Günther Raspotnig (University of Graz, Austria) and Marko Rohlfs (University of Bremen, Germany), agreed to take over the editorial responsibilities as Editors in Chief. To enable a smooth transition, we will run the journal as a trio for the second half of 2018, until my resignation becomes effective at the end of the year.

Günther and Marko will present their vision for the future of Chemoecology in one of the next issues and I wish them every success in developing their ideas for our journal.
Michael Heethoff

heethoff@bio.tu-darmstadt.de

1 Ecological Networks, Technische Universität Darmstadt, Schnittspahnstr. 3, 64287 Darmstadt, Germany 